\title{
Outcome of infants of HIV positive mothers following administration of nevirapine drops at secondary level referral centre
}

\author{
Chandra B.V. Ravi ${ }^{1}$, Krishna K.P. ${ }^{2}$, Viswanath $\mathrm{NGV}^{3}$ \\ ${ }^{1}$ Dr. B.V. Ravi Chandra, Gynaecology, Civil Surgeon Specialist, District Hospital, Vizianagaram, ${ }^{2}$ Dr. K. Prudhvi \\ Krishna, Paediatrics, Civil Assistant Surgeon, District Hospital, Vizianagaram, ${ }^{3}$ Dr. Viswanath NGV, DNB Postgraduate, \\ District Hospital Vizianagaram.
}

Corresponding Author: Dr. K. Prudhvi Krishna, Civil Assistant Surgeon, District Hospital, Vizianagaram, Andhra Pradesh, Email id: drbvrc@gmail.com, k.prudhvi2000@gmail.com

\begin{abstract}
Introduction: Prevention of transmission of HIV to new born and infants through the integration of preventive and care measures. Objective: To assess HIV transmission, adverse reactions and morbidity among neonates and infants born to HIV positive mothers till 18 months of age over a period of 10 years by prevention of mother to child transmission of HIV. Methods: The study was conducted at Department of Obstetrics and Gynecology and Department of Paediatrics, secondary level referral centre, MCH block, District hospital, Vizianagaram, Andhra Pradesh, India. The data was collected during May 2009 to May 2018 from records of maternal details registered at PPTCT clinic as well as list of infants undergoing Early Infant Diagnosis (EID) recorded in the standard format as per instructions from National AIDS Control Organization (NACO) of India. The study was based on administration of Nevirapine drops and Cotrimoxazole syrup as per the guidelines of National AIDS Control Organization (NACO). Results: A total of 68,000 babies were born during 2009 to 2018, of which 63320 were live born, among them 152 were born to HIV positive mothers. All the 152 babies were given Nevirapine drops immediately after delivery followed by cotrimoxazole syrup and tested for HIV antibodies at 6 months, 12 months and 18months of age. Amongst all the babies born to HIV positive mothers, only one baby was HIV reactive, and moreover no baby developed any life threatening adverse reaction in this study. Conclusion: The follow up study of new born babies of HIV positive mothers on Nevirapine drops is found to be effective and may be continued as per the guidelines of NACO.
\end{abstract}

Key words: Cotrimoxazole, HIV positive, NACO, Nevirapine

\section{Introduction}

The National AIDS Control Programme (NACP) under Ministry of Health and Family Welfare, Government of India was implemented in 1992 with an aim to end AIDS by 2030 through integration of prevention and care, support and treatment programmes $[1,2]$. As per 2017 HIV estimation report, India had around 21.40 lakh people living with HIV with adult prevalence estimated at $0.22 \%$.

Around 87.58 thousand new HIV infections and 69.11 thousand AIDS related deaths happened in 2017 while around 22,675 mothers needed Antiretroviral Therapy (ART) for prevention of mother to child transmission (MTCT) of HIV [3]. Globally, HIV infections among new born and infants are almost all due to MTCT,

Manuscript received: $10^{\text {th }}$ May2019

Reviewed: $20^{\text {th }}$ May 2019

Author Corrected: $26^{\text {th }}$ May 2019

Accepted for Publication: $30^{\text {th }}$ May 2019 occurring during pregnancy, during labor and delivery, or through breastfeeding. Early detection and following ART to HIV positive mothers may greatly lower the chance of passing the virus to their babies $[4,5,6]$. Prevention of Parent To Child Transmission (PPTCT) of HIV/AIDS is an integral component of AIDS control programme to halt MTCT of HIV [7].

Based on the current policy of NACO, India, is to prescribe lifelong Antiretroviral Therapy (ART) to all seropositive pregnant women regardless of CD4 count or WHO clinical stage, both for their own health and to prevent vertical HIV transmission from mother to child [8].Keeping the above aspects in view, the present study was conducted to evaluate the impact of ART to mothers and Anti Retroviral Prophylaxis (ARV) to infants to control and reduce the spread of parent to child transmission of HIV. 


\section{Materials and Methods}

The analytical study was conducted at secondary level referral centre at $\mathrm{MCH}$ block, District hospital, Vizianagaram, Andhra Pradesh state. Retrospective data collected over a period of 10 years i.e. 2009 to 2018 from records of maternal details registered at PPTCT clinic as well as list of infants undergoing Early Infant Diagnosis (EID) recorded in the standard format as per instructions from National AIDS Control Organization (NACO) of India. The study was evaluated as per the guidelines given by NACO.

The mother and child hospital has a very high delivery turnover which is approximately 8000 per year with 25 to 30 per cent caesarean rate. The hospital has attached ICTC/PPTCT/HCTC centre for providing antenatal screening for HIV to all pregnant mothers. Those pregnant women reactive for HIV will be counselled and advised ART irrespective of CD 4 count and follow up will be continued till delivery. Neonates will be given Nevirapine immediately after birth and continued for 6weeks if mother was on ART for more than 24 weeks and 12 weeks if the mother was on ART for less than 24 weeks. Babies were screened for HIV DNA
PCR at 6 weeks of life. If HIV DNA PCR is positive, test will be repeated and ART is advised if it was positive for second time. If PCR was negative baby will be screened for antibodies at $6^{\text {th }}, 12^{\text {th }}$ and $18^{\text {th }}$ months and baby will be considered negative if antibodies not detected at 18 months of age and42days after stopping breast feeding. All these babies were advised direct breast feeding as the formula feeding is expensive and the rate of transmission of HIV is more in mixed feeding.

All the babies were advised cotrimoxazole prophylaxis up to 18 months of age till the baby was declared as HIV negative. Treatment of HIV positive antinetal women was based on the existing NACO recommendations. All the HIV positive antenatal women treated with combination of Efavirenz (600mg), Lamivudine (300 $\mathrm{mg}$ ) and Tenofovir Disoproxil (300 mg). A total of 152 mother baby pairs were given ART prophylaxis.

Statistical Analysis- The data collected was subjected to statistical analysis using software package SPSS version20.0. The results are expressed in percentage.

\section{Results}

A total of 87, 066 antenatal cases were registered and screened for HIV during May 2009 to May 2018 i.e 10 years period, out of which 152 cases were found to be positive which is shown in Table no 1.

Table No-1: Year wise distribution of antenatal cases for HIV screening.

\begin{tabular}{|c|c|c|c|}
\hline Year & ANC Screened & ANC positive & Percent \\
\hline $2009-2010$ & 9944 & 30 & 0.30 \\
\hline $2010-2011$ & 9058 & 25 & 0.27 \\
\hline $2011-2012$ & 9042 & 17 & 0.18 \\
\hline $2012-2013$ & 9303 & 12 & 0.12 \\
\hline $2013-2014$ & 9638 & 18 & 0.18 \\
\hline $2014-2015$ & 9479 & 13 & 0.13 \\
\hline $2015-2016$ & 8986 & 11 & 0.12 \\
\hline $2016-2017$ & 10110 & 13 & 0.12 \\
\hline $2017-2018$ & 11506 & 13 & 0.17 \\
\hline TOTAL & 87066 & 152 & 0.11 \\
\hline
\end{tabular}

The incidence of HIV infection is gradually reducing from $0.30 \%$ in 2009 to $0.11 \%$ in 2018 with total $0.17 \%$ in 10 years. For all positive cases husbands were screened for HIV. Out of 152 cases, 126 husbands were positive for HIV and remaining were negative. Out of these 152 seropositive antenatal women, 10 women opted for MTP, 120 delivered through NVD and 22 underwent LSCS. Out of these 139 were live born and 3 babies were stillborn due to come antenatal causes as shown in Fig.1. Among all the seropositive women delivered at our hospital, average cesarean and normal vaginal delivery rate was $14 \%$ and $79 \%$ respectively. These 139 babies were screened for HIV DNA at 6 weeks and followed up for 18 months as per NACO schedule and found one baby was positive for HIV. 
Original Research Article

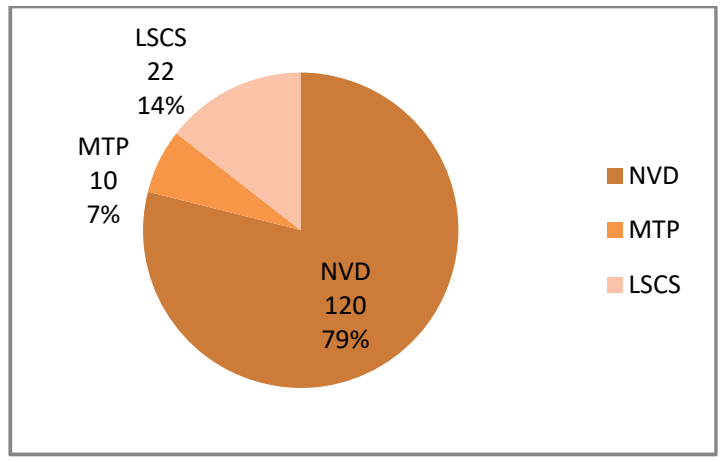

Fig.-1: Outcome of antenatal cases positive in screening

\section{Discussion}

Although, children represent only 6 per cent of all people infected with HIV/AIDS as of December 2005, they account for 18 represent of the 3.1 million AIDS deaths in 2005 [9]. As vertical transmission is the predominant route of HIV from mother to child WHO has initiated PMTCT programmes. The Prevention of Parent to Child Transmission of HIV/AIDS (PPTCT) programme was launched in the country in the year 2002 following a feasibility study in 11 major hospitals in the five high HIV prevalence states. As on $31^{\text {st }}$ August 2016 in India there are 20,756 Integrated Counselling and Testing Centres (ICTC), most of these in government hospitals, which offer PPTCT services to pregnant women [10]. In the present study, there was gradual decline of HIV infection over a period of 10 years. With the use of prevention and care, support and treatment programmes like HIV testing during pregnancy, counselling to seropositive antenatal women and follow up of ART may greatly lower the chance of MTCT of HIV to neonates [11].

In the developing world, where extended breastfeeding until age $\sim 2$ years is the predominant practice, the rate of MTCT is estimated to be $5 \%$ to $10 \%$ during pregnancy $10 \%$ to $15 \%$ during labor, and $15 \%$ to $20 \%$ during prolonged breastfeeding when strategies to reduce HIV transmission are not adopted [5,12]. The risk of PTCT is high if the mother acquire primary HIV infection during lactation period or seroconversion takes place during feeding period which can be missed during antenatal screening programme $[13,14]$.

Transmission of HIV through breastfeeding may happen at any time during lactation. The early postnatal period (before 6-8 weeks of breastfeeding) appears to be a particularly high-risk time for HIV transmission $[15,16]$. AAP recommends that HIV-infected mothers not breastfeed their infants, regardless of maternal viral load and antiretroviral therapy [17]. Some African studies reported a significant reduction in HIV transmission through breast feeding with ART prophylaxis for 6 weeks to infant with Nevirapine or triple regimen to mother [18] and based on these studies WHO issued revised guidelines to PPTCT. Cotrimoxazole prophylaxis in HIV infected children in all ages to prevent opportunistic infection [19]. Cotrimoxazole prophylaxis is safe, inexpensive and highly effective in reducing morbidity and mortality among HIV-infected infants and children, as well as in adolescents and adults. Ideally, all infants exposed to HIV should be started on co-trimoxazole prophylaxis during the first four to six weeks of life, as recommended by the World Health Organization (WHO) $[20,21]$. The district hospital, Viziznagaram located in Andhra Pradesh State with its MCH block providing exclusive services to mother and child.

This MCH block is provided with ICTC now named HCTC i.e. HIV Counselling and Testing centre with objective of ante natal screening and implementation of NACO's PPTCT guidelines. This centre is connected to ART centre District Hospital, Vizianagaram, Andhra Pradesh. About 68000 deliveries were conducted in this hospital during the period 2009 to 2018, 67320 live babies were born and 152 babies were examined under PPTCT protocol all babies were negative except one baby which was positive due to lack of proper follow up by mother due to migration. This indicates the vertical transmission from mother to child can be prevented successfully with proper implementation of PPTCT which makes vertical transmission near Zero.

All these babies were screened for cotrimoxazole side effects and one baby had shown signs of Steven Johnson syndrome of mild variant responded well to treatment and no life threatening adverse reactions were noted. As all these babies were on mothers milk current PPTCT protocol can prevent HIV transmission through mother's milk as mothers are on ART and babies were on Nevirapine drops. 


\section{Conclusion}

Till to date there is no effective vaccine or specific drug to cure or eradicate HIV infection or AIDS but HAART or MDT can change the disease process, course of the disease and prolongs life span of the individual with HIV infection.

PPTCT is a successful initiative to prevent vertical transmission from parent to child which will reduce HIV incidence in children.

The present protocol is highly efficacious with very few side effects can be continued till new effective vaccine or immuno-modulators are available for HIV.

Author Contributions- Dr. Ravi Chandra planned and coordinated this study. Dr. Ravi Chandra and Dr. Prudhvi Krishna collected data and done data analysis. Dr. Ravi Chandra, Dr. Prudhvi Krishna and Dr. Vishwanath drafted the manuscript.

Funding: Nil, Conflict of interest: None initiated, Permission from IRB: Yes

\section{References}

1.National AIDS Control Organization (NACO): Annual Report 2017-2018. Ministry of Health and female welfare, India. 24: 355-403; Available from: http:// www.naco.gov.in.

2. Ramachandran R, Chandrasekaran V, Muniyandi M, Jaggarajamma K, Bagchi A, Sahu S. Prevalence and Risk Factors of HIV Infection among Clients Attending ICTCs in Six Districts of Tamilnadu, South India. HARTOJ. 2011; 2011: 1-7. doi:10.1155/2011/650 321.

3. National AIDS Control Organization (NACO) releases HIV Estimations 2017. 14 SEP 2018 3:39PM; PIB Delhi, Ministry of Health and Family Welfare, Government of India.

4. The Working Group on Mother-to-Child Transmission of HIV. Rates of mother-to- child transmission of HIV-1 in Africa, America, and Europe: results from 13 perinatal studies. J Acquir Immune Defic Syndr Hum Retrovirol. 1995; 8(5):506-510

5. De Cock KM, Fowler MG, Mercier E, de Vincenzi I, Saba J, Hoff E, Alnwick DJ, Rogers M, Shaffer N. Prevention of mother-to-child HIV transmission in resource poor countries: translating research into policy and practice. JAMA. 2000; 283(9):1175-1182.
6. Children with HIV and AIDS [Internet]. 2018 [cited 2018 Dec 14]. Available from: https://www.webmd. com /hiv-aids/ guide/hiv-in-children\#1-2.

7. Chukwuemeka IK, Fatima MI, Ovavi ZK, Olukayode O. The impact of a HIV prevention of mother to child transmission program in a Nigerian early infant diagnosis centre. Niger Med J. 2014; 55 (3): 204-08.

8. WHO. Consolidated Guidelines on the use of antiretroviral drugs for treating and preventing HIV Infection: recommendations for a public health approach. Geneva: WHO Press 2013. Available from: http://apps. who.int/iris/ bitstream/ 10665/85321 /1/ 9789241505727_eng.pdfua=1.

9. Pediatric Antiretroviral Therapy (ART)Antiretroviral Therapy (ART) Guidelines [Internet]. 2014. Available from: http://naco.gov.in/sites/default/files/Pediatric_1403-2014.pdf.

10. National AIDS Control Organization (NACO): Annual Report 2016-2017. Ministry of Health and female welfare, India. 24: 355-403; Available from: http: // www.naco.gov.in.

11. Robert MK, Bonita MDS, Joseph SG, Nina FS, Richard EB. Nelson text book of paediatrics, 1 Volume. Philadelphia, United States. Elsevier - Health Sciences Division. 2011.

12. The Working Group on Mother-to-Child Transmission of HIV. Rates of mother-to-child transmission of HIV-1 in Africa, America, and Europe: results from 13 perinatal studies. J Acquir Immune Defic Syndr Hum Retrovirol. 1995; 8 (5):506-510 pmid: 7697448

13. Perre PV de, Simonon A, Msellati P, Hitimana DG, Vaira D, Bazubagira A, Goethem CV, Stevens AM, Karita E, Thull DS, Dabis F, Lepage P. Postnatal transmission of human immunodeficiency virus type 1 from mother to infant - A prospective cohort study in Kigali, Rwanda. N Engl J Med. 1991; 325 (9): 593-598.

14. Dunn DT, Newell ML, Ades AE, Peckham CS. Risk of human immunodeficiency virus type 1 transmission through breastfeeding. Lancet. 1992 Sep 5; 340(8819): 585-588. 
15. Nduati R, John G, Mbori-Ngacha D, Richardson B, Overbaugh J, Mwatha A, Ndinya-Achola J, Bwayo J, Onyango FE, Hughes J, Kreiss J. Effect of breastfeeding and formula feeding on transmission of HIV-1: a randomized clinical trial. JAMA. 2000 Mar 1; 283 (9): $1167-1174$

16. Dunn DT, Tess BH, Rodrigues LC, Ades AE. Mother-to-child transmission of HIV: implications of variation in maternal infectivity. AIDS. 1998; 12(16): 2211-2216

17. Committee on pediatric AIDs. Policy statement: Infant feeding and transmission of human immuno deficiency virus in the United States.Pediatrics. 2013 Feb; 131 (2): 391-396.

18.MofensonLM. Antiretroviral drugs to prevent breastfeeding HIV transmission.Antivir Ther. 2010; 15 (4): 537-553.doi: 10.3851/IMP1574.
19. Chintu C, Bhat GJ, Walker AS, Mulenga V, Sinyinza F, Lishimpi K, Farrelly L, Kaganson N, Zumla A, Gillespie SH, Nunn AJ, Gibb DM; CHAP trial team. Co-trimoxazole as prophylaxis against opportunistic infections in HIV-infected Zambian children (CHAP): a double-blind randomised placebo-controlled trial. Lancet. 2004 Nov 20-26; 364(9448):1865-71.

20. WHO issues guidelines on use of Co-trimoxazole prophylaxis [Internet]. 2006. Available from: http:// www.aidsmap.com/WHO-issues-guidelines-on-use-ofcotrimoxazoleprophylaxis/page/1424561/.

21. Co-trimoxazole prophylaxis for HIV-exposedand HIV-infected infants and children: Practical approaches to implementation and scale up. Geneva: WHO Press 2009.Available from: https://www.unicef.org/ aids/files/ Cotrimoxazole Guide_2009.pdf.

\section{How to cite this article?}

Chandra B.V. Ravi, Krishna K.P, Viswanath NGV. Outcome of infants of HIV positive mothers following administration of nevirapine drops at secondary level referral centre. Int J Pediatr Res. 2019; 6(06):272-276.doi:10.17511/ ijpr.2019.i06.02 